\title{
Long-Term Dietary Strawberry, Spinach, or Vitamin E Supplementation Retards the Onset of Age-Related Neuronal Signal-Transduction and Cognitive Behavioral Deficits
}

\author{
J. A. Joseph, ${ }^{1}$ B. Shukitt-Hale, ${ }^{1}$ N. A. Denisova, ${ }^{1}$ R. L. Prior,${ }^{1}$ G. Cao, ${ }^{1}$ A. Martin, ${ }^{1}$ \\ G. Taglialatela, ${ }^{2}$ and P. C. Bickford ${ }^{3}$ \\ 1 United States Department of Agriculture Human Nutrition Research Center on Aging at Tufts, Boston, Massachusetts \\ 02111, 2Department of Chemistry and Genetics, University of Texas, Galveston, Texas 77555, and ${ }^{3}$ Department of \\ Veteran's Affairs Medical Center, Denver, Colorado 80262
}

Recent research has indicated that increased vulnerability to oxidative stress may be the major factor involved in CNS functional declines in aging and age-related neurodegenerative diseases, and that antioxidants, e.g., vitamin E, may ameliorate or prevent these declines. Present studies examined whether long-term feeding of Fischer 344 rats, beginning when the rats were 6 months of age and continuing for 8 months, with diets supplemented with a fruit or vegetable extract identified as being high in antioxidant activity, could prevent the age-related induction of receptor-mediated signal transduction deficits that might have a behavioral component. Thus, the following parameters were examined: (1) oxotremorine-enhanced striatal dopamine release (OX-K ${ }^{+}$-ERDA), (2) cerebellar $\beta$ receptor augmentation of GABA responding, (3) striatal synaptosomal ${ }^{45} \mathrm{Ca}^{2+}$ clearance, (4) carbachol-stimulated GTPase activity, and (5) Morris water maze performance. The rats were given control diets or those supplemented with strawberry extracts (SE), $9.5 \mathrm{gm} / \mathrm{kg}$ dried aqueous extract (DAE), spinach (SPN 6.4 $\mathrm{gm} / \mathrm{kg} \mathrm{DAE})$, or vitamin E (500 IU/ $/ \mathrm{kg})$. Results indicated that SPN-fed rats demonstrated the greatest retardation of ageeffects on all parameters except GTPase activity, on which SE had the greatest effect, whereas SE and vitamin $E$ showed significant but equal protection against these age-induced deficits on the other parameters. For example, OX-K ${ }^{+}$-ERDA enhancement was four times greater in the SPN group than in controls. Thus, phytochemicals present in antioxidant-rich foods such as spinach may be beneficial in retarding functional age-related CNS and cognitive behavioral deficits and, perhaps, may have some benefit in neurodegenerative disease.

Key words: antioxidants; aging; diet; dopamine; GABA; norepinephrine; striatum; cerebellum; cognitive behavior
It is well known that there are numerous declines in central neuronal functioning that can occur in aging in the absence of neurodegenerative disease. These alterations may be manifested as a loss of neurotransmitter receptor sensitivity such as: (1) muscarinic (Amenta et al., 1989; Araujo et al., 1990; Joseph et al., 1990; Sherman and Friedman, 1990; Vannucchi, 1991; Viana et al., 1992; Yufu et al., 1994; Egashira et al., 1996), (2) adrenergic (Burnett et al., 1990; Gelbmann and Muller, 1990; Gould and Bickford, 1997), (3) dopaminergic (Joseph et al., 1978; Roth and Joseph, 1994; Gould et al., 1996; Volkow et al., 1996; Araki et al., 1997; Zhang et al., 1997; Levine and Cepeda, 1998), and (4) opioid (Dondi et al., 1992; Kornhuber et al., 1996; Nagahara et al., 1996).

Although a great deal of research has been devoted toward the delineation of the most critical factors that may account for this functional neuronal loss in aging and enhanced loss in age-related neurodegenerative diseases [Alzheimer's (AD) and Parkinson's

\footnotetext{
Received April 14, 1998; revised July 13, 1998; accepted July 20, 1998.

This work was supported by the United States Department of Agriculture (USDA) and United States Public Health Service Grants AG04418, AG007728, and VA MRS. We thank Dr. Donna Bilinski for her valuable help with this manuscript and Mr. Donald E. Smith of the animal care staff (Department of Comparative Biology and Medicine) of the USDA Human Nutrition Research Center at Tufts University for the feeding and maintenance of the rats used in this study.

Correspondence should be addressed to Dr. J.A. Joseph, United States Department of Agriculture Human Nutrition Research Center on Aging at Tufts University, Room 919, 711 Washington Street, Boston, MA 02111.

Copyright (C) 1998 Society for Neuroscience $\quad 0270-6474 / 98 / 188047-09 \$ 05.00 / 0$
}

(PD) diseases], their specification has been elusive. However, recent studies have suggested that one of the most important may be age-related decrements in the ability to mitigate long-term oxidative stress (OS) effects. For example, OS may be a primary etiological factor in both AD (Finch and Cohen, 1997) and PD (Jenner, 1996), and there are increases in OS vulnerability as a function of age (Joseph et al., 1996). Evidence also indicates that there are reductions in endogenous antioxidants in aging (e.g., glutathione, Ohkuwa et al., 1997; and glutamine synthetase, Carney et al., 1994), with increases in lipid peroxidation (Migheli et al., 1994; Yu, 1994).

Given these considerations, we believed that it might be possible to counter dietarily the decreases in antioxidant protection that occur in aging by increasing the intake of fruits and vegetables identified as being high in antioxidant activity (Yamori and Horie, 1994; Cao et al., 1995, 1996; Meydani et al., 1995; Taylor and Nowell, 1997; Wang et al., 1996). Such consumption has already been found to reduce cancer incidence (Doll, 1990; Willett, 1994a,b) and ischemic heart disease (Hughes, 1995; Mayne, 1996).

In the brain, the consumption of the flavonoid glycosides of ginkgo biloba decreased memory impairment (Rai et al., 1991), difficulties in concentration (Kleijnen and Knipshild, 1992a,b), $\mathrm{Ca}^{+2}$-induced increases in neuronal oxidative metabolism (Oyama et al., 1993, 1994), and AD progression (Kanowski et al., 1996). Thus, present research was directed toward determining if the early appearance of decrements in receptor sensitivity (at 15 
Table 1. Diets fed to rats (for 8 months, from age 6-15 months)

Diet composition $(\mathrm{gm} / \mathrm{kg})$

\begin{tabular}{|c|c|c|c|c|}
\hline \multirow[b]{2}{*}{ Ingredient } & & & & \\
\hline & Control & + Strawberry & + Spinach & +Vitamin E \\
\hline Casein, alcohol-extracted & 189.6 & 189.6 & 189.6 & 189.6 \\
\hline L-Cystine & 2.8 & 2.8 & 2.8 & 2.8 \\
\hline Corn starch & 450.2 & 440.7 & 443.8 & 449.2 \\
\hline Maltodextrin 10 & 118.5 & 118.5 & 118.5 & 118.5 \\
\hline Sucrose & 94.8 & 94.8 & 94.8 & 94.8 \\
\hline Cellulose, BW200 & 47.4 & 47.4 & 47.4 & 47.4 \\
\hline Soybean oil & 42.7 & 42.7 & 42.7 & 42.7 \\
\hline Salt $\operatorname{mix}^{a}$ & 9.5 & 9.5 & 9.5 & 9.5 \\
\hline $\mathrm{CaPO}_{4}$, dibasic & 12.3 & 12.3 & 12.3 & 12.3 \\
\hline $\mathrm{CaCO}_{3}$ & 5.2 & 5.2 & 5.2 & 5.2 \\
\hline Potassium citrate & 15.6 & 15.6 & 15.6 & 15.6 \\
\hline Sodium selenite & 0.00009 & 0.00009 & 0.00009 & 0.00009 \\
\hline Vitamin mix $(\mathrm{V} 13401)^{b}$ & 9.5 & 9.5 & 9.5 & 9.5 \\
\hline Choline bitartrate & 1.9 & 1.9 & 1.9 & 1.9 \\
\hline Strawberry extract ${ }^{c}$ & & 9.5 & & 0 \\
\hline Spinach extract ${ }^{c}$ & & & 6.4 & \\
\hline Vitamin E acetate, $500 \mathrm{IU}$ & & & & 1 \\
\hline Total & 1000 & 1000 & 1000 & 1000 \\
\hline
\end{tabular}

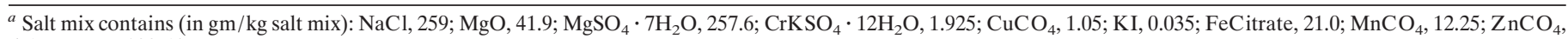
5.6; sucrose, 399.64.

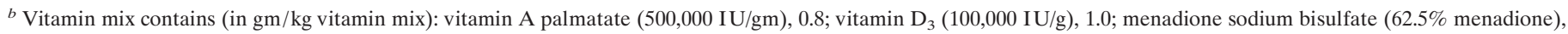

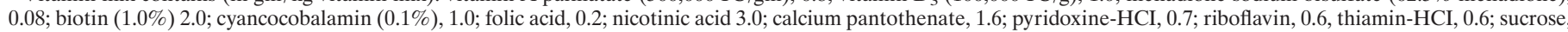
988.42 .

${ }^{c}$ Freeze-dried aqueous extract $\left(1 \mathrm{gm}\right.$ fresh weight plus $\left.2 \mathrm{~mL} \mathrm{H}_{2} \mathrm{O}\right)$ prepared by homogenizing, centrif uging, and then freeze drying.

months of age in Fischer 344 rats), loss of calcium homeostasis (Landfield and Eldridge, 1994), and cognitive performance could be prevented by 8 months (6-15 months) of feeding of a control diet or diets containing vitamin E or extracts of strawberries or spinach. Strawberries and spinach have been identified previously (Cao et al., 1995, 1996; Wang et al., 1996) by the oxygen radical absorbance capacity (ORAC) assay as being high in antioxidant activity.

\section{MATERIALS AND METHODS}

\section{Animals}

The subjects consisted of 80 male Fischer 344 rats (Harlan Sprague Dawley, Indianapolis, IN). The rats were individually housed in stainless steel mesh suspended cages, provided food and water ad libitum, and maintained on a $12 \mathrm{hr}$ light/dark cycle. All animals were observed daily for clinical signs of disease.

After a $12 \mathrm{~d}$ acclimatization period to the facility, the 6-month-old rats were weight-matched, given 2 weeks on the control (modified AIN-93) diet (Table 1), and randomly assigned to one of four groups: control diet, or the control diet supplemented with 500 IU vitamin E acetate, $0.95 \%$ $(\mathrm{w} / \mathrm{v})$ strawberry extract, or $0.64 \%$ spinach extract (Table 1$)$. They were fed these diets for 8 months before experimental testing. The amounts of strawberry or spinach extracts added into the control diets were based on an equivalent ORAC activity so that each diet provided equivalent antioxidant activity ( $1.36 \mathrm{mmol}$ Trolox equivalent per kilogram of diet). Monthly weights and food intakes (over a $48 \mathrm{hr}$ period) were recorded. These animals were used in compliance with all applicable laws and regulations as well as principles expressed in the National Institutes of Health, United States Public Health Service Guide for the Care and Use of Laboratory Animals. This study was approved by the Animal Care and Use Committee of our center.

\section{Diet preparation}

We added $400 \mathrm{gm}$ of sample to water in the ratio of 2:1 for strawberries and spinach, then homogenized it in a blender for $2 \mathrm{~min}$. The recovered homogenate was centrifuged at $13,000 \times g$ for $15 \mathrm{~min}$ at $4^{\circ} \mathrm{C}$. The supernatant was then recovered and combined in freezer bags, 500 $\mathrm{ml} / \mathrm{bag}$. The extract was frozen and then crushed and placed in the freeze drier until dry, which usually required $\sim 7 \mathrm{~d}$. The freeze-dried extracts were shipped to Research Diets Inc. (New Brunswick, NJ) where they were combined with a control diet (Table 1). The amount of corn starch in the control diet was adjusted accordingly when vitamin $\mathrm{E}$ acetate and strawberry or spinach extracts were added.

\section{Procedures}

Dopamine release. Dopamine (DA) release was conducted as previously described (Joseph et al., 1988a,b; 1990). Briefly, cross-cut (300 $\mu \mathrm{m}$, McIlwain tissue chopper) striatal slices were obtained from the animals maintained on the various diets. The slices were placed in small glass vials containing modified Krebs'solution-Ringer's solution basal release medium (BRM) that had been bubbled for 30 min with $95 \% \mathrm{O}_{2}$ and $5 \%$ $\mathrm{CO}_{2}$ and which contained (in $\mathrm{mm}$ ) $\mathrm{NaHCO}_{3} 21$, glucose 3.4, $\mathrm{NaH}_{2} \mathrm{PO}_{4}$ 1.3, EGTA 1, $\mathrm{MgCl}_{2}$ 0.93, $\mathrm{NaCl} 127$, and $\mathrm{KCl} 2.5$ (low $\mathrm{KCl}$ ), $\mathrm{pH}$ 7.4. They were then placed in the perfusion chambers in which they were maintained at $37^{\circ} \mathrm{C}$ and perfused with the BRM for $30 \mathrm{~min}$. After this equilibration period, the medium was then switched to one containing (in $\mathrm{mm}$ ) $\mathrm{KCl} 30, \mathrm{CaCl}_{2} \cdot 2 \mathrm{H}_{2} \mathrm{O} 1.26$ (in place of EGTA), and $\mathrm{NaCl} 57$ and 0 or $500 \mu \mathrm{M}$ oxotremorine, and the enhancement of $\mathrm{K}^{+}$-evoked striatal dopamine release $\left(\mathrm{K}^{+}\right.$-ERDA) was assessed. DA release was then quantitated by HPLC coupled to electrochemical detection. Data were expressed as picomoles per milligram of protein as determined by the Lowry procedure (Lowry et al., 1951).

Electrophysiology. Rats from the various diet groups were anesthetized with urethane $(0.75-1.25 \mathrm{gm} / \mathrm{kg})$, intubated, and allowed to breath spontaneously. Corneal reflex and toe pinch was used to monitor anesthetic level to establish equal planes of anesthesia. A heating pad was used to maintain body temperature at $37^{\circ} \mathrm{C}$. Animals were placed in a stereotaxic frame, and the skin and muscle over the posterior vermis was removed. The cistern was drained, and the skull and dura over the vermis were removed. A solution of $2 \%$ agar in saline covered the brain. Recordings were made in lobules VI and V II of cerebellar vermis from Purkinje cells as identified by anatomical location and the characteristic complex spiking of Purkinje cells.

Neuronal signals were amplified and filtered $(-3 \mathrm{~dB}$ at 0.3 and $5 \mathrm{kHz})$ and displayed on a storage oscilloscope. Action potentials were isolated using a window discriminator, and the output was displayed using a strip 
chart recorder. Single units had to have a signal-to-noise ratio of at least 2:1. Multibarrel glass micropipettes were used for single-cell recording and local drug application via microiontophoresis (resistance of the recording electrodes $1.5-3.3 \Omega$ ). In the multibarrel glass micropipettes, two barrels were filled with $3 \mathrm{M} \mathrm{NaCl}$, and the other two barrels were filled with GABA $(0.25 \mathrm{M}, \mathrm{pH} 4.0-4.5)$ and with the $\beta$-adrenergic agonist, isoproterenol (ISO) $(0.25 \mathrm{M}, \mathrm{pH} 4.0-4.5)$, respectively. A constant current source provided ejection and retaining currents for the drug barrels and passed an equal current of opposite polarity through the balance barrel to neutralize the tip potential. Uniform pulses of drug were applied at regular intervals.

GABA was locally applied by microiontophoresis to produce a $10-$ $30 \%$ inhibition of spontaneous firing rates. Isoproterenol was then applied concurrently until either a change in the response to GABA was observed or a change in baseline spontaneous rate was observed. Four applications of GABA were given before ISO was coadministered.

After ISO was turned off, GABA was given until it could be determined if the pre-ISO level of GABAergic inhibition would return. Only cells in which the post-ISO level of GABAergic inhibition matched the pre-ISO level of GABAergic inhibition were analyzed. Drug-induced responses were quantified by computer. The rate meter data were digitized, and the percent inhibitions of firing rate resulting from drug applications were calculated.

${ }^{45}$ Ca recovery. Striatal synaptosomes were isolated from the individual Fischer 344 rats as described previously (Yeh et al., 1993). The final pellets of Ficoll-purified synaptosomes were washed twice and resuspended in the basal medium (B-cond, in mM: $136 \mathrm{NaCl} ; 5 \mathrm{KCl} ; 1.2$ $\mathrm{CaCl}_{2} ; 1.3 \mathrm{MgCl}_{2} ; 10$ glucose; and 20 Tris, $\mathrm{pH} \mathrm{7.65)}$ at the protein concentration $1-1.3 \mathrm{mg} / \mathrm{ml}$. Aliquots of synaptosomes $(50 \mu \mathrm{l})$ were preincubated for $5 \mathrm{~min}$ at $37^{\circ} \mathrm{C}$ with constant shaking. OS in synaptosomes was induced by adding $\mathrm{H}_{2} \mathrm{O}_{2}$ (final concentration $300 \mu \mathrm{M}$ ) for $15 \mathrm{~min}$. ${ }^{45} \mathrm{Ca}$ uptake studies were performed as described (Leslie et al., 1980). The ${ }^{45} \mathrm{Ca}$ uptake was started by transferring oxidized and control synaptosomes to basal medium or depolarizing medium (D-cond, in mM: 60 $\mathrm{KCl} ; 1.2 \mathrm{CaCl}_{2} ; 1.3 \mathrm{MgCl}_{2} ; 10$ glucose; and 20 Tris, $\mathrm{pH}$ 7.65). Both media had previously been supplemented with ${ }^{45} \mathrm{CaCl}_{2}(2 \mu \mathrm{Ci})$. The reaction was stopped after $2 \mathrm{~min}$ by rapid filtration of samples through Whatman GF/B (Maidstone, UK) filters, followed by washing three times with ice-cold stop medium (in mM: $136 \mathrm{NaCl} ; 5 \mathrm{KCl} ; 3$ EGTA; 1.3 $\mathrm{MgCl}_{2} ; 10$ glucose; and 20 Tris, $\left.\mathrm{pH} 7.65\right)$ by using vacuum filtration (BRANDEL, model ML-48). The radioactivity retained in the filters was measured by a liquid scintillation counter (WALLAC 1409; WALLAC Oy, Turku, Finland) programmed for automatic quenching correction. Results were expressed as nanomoles of $\mathrm{Ca}^{2+}$ per milligram of protein. Percent of increase in ${ }^{45} \mathrm{Ca}$ uptake (Increase) and recovery at $30 \mathrm{sec}$ after depolarization (Recovery) were calculated as follows:

Increase $=\frac{{ }^{45} \mathrm{Ca} \text { uptake }(\mathrm{D} \text {-cond })-{ }^{45} \mathrm{Ca} \text { uptake }(\mathrm{B}-\text { cond })}{{ }^{45} \mathrm{Ca} \text { uptake }(\mathrm{B}-\text { cond })}$

$\times 100 \%$

Recovery $=\frac{{ }^{45} \mathrm{Ca} \text { uptake }(\mathrm{D} \text {-cond })-{ }^{45} \mathrm{Ca} \text { uptake }(\mathrm{D} \text {-cond at } 30 \mathrm{sec})}{{ }^{45} \mathrm{Ca} \text { uptake }(\mathrm{D} \text {-cond })-{ }^{45} \mathrm{Ca} \text { uptake }(\mathrm{B} \text {-cond })}$

$\times 100 \%$

Cognitive testing. The working memory version of the Morris water maze (MWM), with a 10 min intertrial interval, was performed to test spatial learning and memory (Morris, 1984; Brandeis et al., 1989). Performance on the maze, including the working memory paradigm, has been shown to deteriorate with aging (Gage et al., 1984; Rapp et al., 1987; Gallagher and Pelleymounter, 1988; Brandeis et al., 1989; Van der Staay and de Jonge, 1993; Ingram et al., 1994) because of a specific deficit in the ability of aged rats to use spatial information (Rapp et al., 1987).

For these experiments, the maze consisted of a circular black fiberglass pool $(134 \mathrm{~cm}$ in diameter $\times 50 \mathrm{~cm}$ in height), filled to a depth of $30 \mathrm{~cm}$ with water maintained at $23^{\circ} \mathrm{C}$. The pool was divided into four equal-size quadrants. The circular escape platform $(10 \mathrm{~cm}$ in diameter) was colored black and, therefore, hidden from sight. The platform was submerged 2 $\mathrm{cm}$ below the surface of the water in the center of one of the quadrants; its location was changed to a different quadrant for each session of testing. The maze was placed in a room with the lights dimmed, and there were numerous extramaze cues on the walls.

MWM testing was performed daily for 4 consecutive d, with a morning and an afternoon session, two trials each session, with a 10 min intertrial interval between the two trials. At the beginning of each trial, the rat was gently immersed in the water at one of four randomized start locations (located $90^{\circ}$ apart on the perimeter of the pool). Each rat was allowed $120 \mathrm{sec}$ to escape onto the platform; if the rat failed to escape within this time, it was guided to the platform. Once the rat reached the platform, it remained there for $15 \mathrm{sec}$ (trial 1, reference memory or acquisition trial). The rat was returned to its home cage between trials $(10 \mathrm{~min})$. Trial 2 (the working memory or retrieval trial) used the same platform location and start position as trial 1. Performance (latency to find platform in seconds, distance swam in centimeters, and swim speed in centimeters per second) on each trial was videotaped and analyzed with image tracking software (HVS Image, Hampton, England).

Analyses of oxidative stress. The effects of oxidative stress on the production of reactive oxygen species (ROS) in the brain tissue obtained from the various diet groups were assessed using $2^{\prime}, 7^{\prime}$ dichlorofluorescein diacetate (DCFH-DA; Molecular Probes, Eugene, OR) analysis (Ueda et al., 1997). It has been shown that DCFH-DA is nonpolar, nonionic, crosses cell membranes, and is enzymatically hydrolyzed by intracellular esterases to nonfluorescent DCFH-DA. In the presence of ROS, DCFH-DA is rapidly oxidized to highly fluorescent $2^{\prime}, 7^{\prime}$-dichlorofluorescein (DCF) (Lebel et al., 1992). For these experiments, striatum and cerebellum were quickly removed from the brain. Pellets of membranes (synaptosomes, myelin, and mitochondria) were obtained as described previously (Denisova et al., 1998). Each pellet was then resuspended in incubation media (IM: in mM: $136 \mathrm{NaCl} ; 5 \mathrm{KCl} ; 1.2$ $\mathrm{CaCl}_{2} ; 1.3 \mathrm{MgCl}_{2} ; 10$ glucose; and 20 Tris, $\left.\mathrm{pH} 7.65\right)$ at the protein concentration $1-1.3 \mathrm{mg} / \mathrm{ml}$. Aliquots (100 $\mu \mathrm{g}$ of protein) were preincubated for $5 \mathrm{~min}$ at $37^{\circ} \mathrm{C}$ with constant shaking. DCF was added to each sample (final concentration $50 \mu \mathrm{M}$ ) for $30 \mathrm{~min}$. Samples were washed, resuspended in IM, and placed on a 96-well plate. Fluorescence was monitored for 15 min on CytoFluor multi-well plate reader (PerSeptive Biosystem, Framingham, MA). The dye was excited at $485 \mathrm{~nm}$, and emission was filtered using $530 \mathrm{~nm}$ filter (slit 20 and 25 for excitation and emission, respectively). The results were expressed as DCF fluorescence.

GTPase activity Striatal membranes were prepared, and low $K_{\mathrm{M}}$ GTPase analysis was performed according to the method of Cassel and Selinger (1976) as modified by Joseph et al. (1998). Briefly, membranes were prepared by homogenizing the striatal tissue in $10 \mathrm{ml}$ of Tris buffer, $50 \mathrm{~mm}, \mathrm{pH} 7.4$, EDTA, $10 \mathrm{~mm}$, and phenylmethylsulfonyl fluoride, 0.1 $\mathrm{mm}$ in a Tekmar Company (Cincinnati, OH) Tissuemizer (setting 5, 5 $\mathrm{sec}$ ). Membranes were then centrif uged at 20,000 $\times \mathrm{g}$ for $10 \mathrm{~min}$, and the pellet was resuspended and washed at the same speed and time and resuspended in $1 \mathrm{ml}$ Tris-EDTA. Membranes (10 ug membrane protein) were then incubated in a reaction mixture containing (in $\mathrm{mM}$ ): $100 \mathrm{NaCl}$; 20 Tris- $\mathrm{HCl}, \mathrm{pH}$ 7.4,; $5 \mathrm{MgCl}_{2}$; 1 ATP; 2 AppNHp; 10 phosphocreatine; 2 dithiothreitol; 0.1 EDTA; 0.1 EGTA; $60 \mathrm{U} / \mathrm{ml}$ creatine phosphokinase; $0.3 \mu \mathrm{M}\left[\gamma_{-}{ }^{32} \mathrm{P}\right] \mathrm{GTP}(\mathrm{NEN}, 30 \mathrm{Ci} / \mathrm{mmol})$ for $10 \mathrm{~min}$ at $37^{\circ} \mathrm{C}$, and carbachol $\left(0,10^{-5}-10^{-3} \mathrm{M}\right)$. After stopping the reaction with $900 \mu \mathrm{l}$ of ice-cold 5\% activated charcoal in $20 \mathrm{~mm}$ phosphoric acid, an aliquot was taken, and radioactivity was determined by liquid scintillation counting. Low $K_{\mathrm{M}}$ GTPase activity was calculated by subtracting the activity measured in the presence of $100 \mu \mathrm{M}$ unlabeled GTP from total activity. Activity was expressed in picomoles of $\left[\gamma^{32} \mathrm{P}\right]$ hydrolyzed per milligram of protein, per minute. Values were expressed as mean \pm SEM of the differences between basal and carbachol-stimulated low $K_{\mathrm{M}}$ GTPase activity $(\Delta G)$ in picomoles per milligram of protein per minute. Proteins were determined by the Lowry et al. (1951) method.

\section{RESULTS \\ Weights and food intakes}

The rats gained weight from 6 to 15 months $\left[F_{(11,36)}=215.44 ; p<\right.$ $0.001]$ from an average of $356.3 \pm 0.4$ precontrol diet to $473.4 \pm$ 3.4 at age 15 months. However, there were no differences in weight between the diet groups over time $(p>0.05)$ or at age 15 months $(p>0.05)$. There were also no differences in food intakes between the diet groups over the course of the study $(p>0.05)$.

\section{DA release}

As can be seen from Figure 1, all striatal slices obtained from the animals in the various diet groups (eight animals per group) showed significantly greater oxo-enhanced $\mathrm{K}^{+}$-ERDA than that 


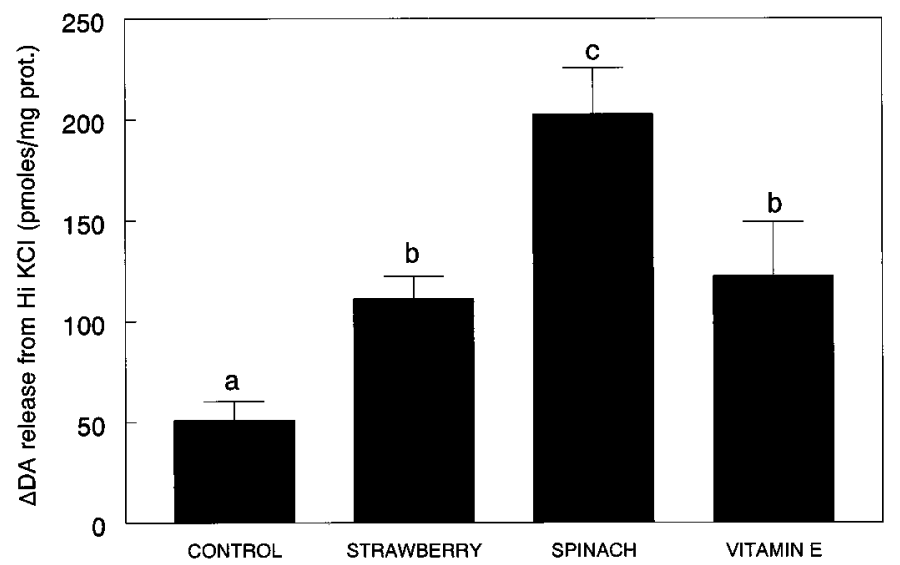

Figure 1. Oxotremorine enhancement of dopamine release from striatal slices obtained and prepared from animals maintained on the control or the various antioxidant diets. For this figure, $a$ differs from the strawberry, spinach, and high vitamin E groups $(p<0.034 ; p<0.0001$; and $p<0.014$, respectively). $c$ differs from the strawberry $(p<0.002)$ and high vitamin $\mathrm{E}(p<0.006)$ groups, whereas $b$ s do not differ from each other $(p>0.05)$.

seen in those obtained from animals maintained on the control $\operatorname{diet}\left[F_{(3,28)}=10.6, p<0.0001\right.$; Fisher's least significant difference test: control vs strawberry, $p<0.03$; control vs spinach, $p<$ 0.0001 ; and control vs vitamin E, $p<0.014]$. Additional post hoc comparisons indicated that oxo-enhanced $\mathrm{K}^{+}$ERDA in the spinach-fed group was greater than the strawberry-fed $(p<$ $0.002)$ or vitamin $\mathrm{E}(p<0.006)$ groups.

\section{Electrophysiology}

Electrophysiological recordings from cerebellar Purkinje neurons indicated that the ability of isoproterenol to modulate GABA inhibitions decreased in the rats maintained on the control diet. When the effect of ISO was tested in aged control rats, as had been seen previously (Gould and Bickford, 1997), only $32 \%$ of the neurons tested demonstrated an ISO augmentation of the GABAergic responses. Aged rats that had been on the vitamin E, strawberry, or spinach diet had significantly more cells that responded to ISO ( $p<0.05$ Fisher's exact test). Examples of ratemeter records for the control and strawberry-supplemented rats are shown in Figure 2, whereas the mean responses for all groups are shown in Figure 3.

\section{${ }^{45}$ Ca recovery}

When differences in ${ }^{45} \mathrm{Ca}$ recovery were examined in the striatal synaptosomes obtained from the controls and various groups, the results indicated that there were significant differences as a function of diet and $\mathrm{H}_{2} \mathrm{O}_{2}$ treatment $\left[F_{(3,26)}=7.79 ; p<0.001\right]$, with all of the diet groups showing greater ${ }^{45} \mathrm{Ca}$ recovery, i.e., a greater ability to extrude or sequester calcium after depolarization than the control group. As shown in Figure $4,{ }^{45} \mathrm{Ca}$ recovery was significantly decreased in the $\mathrm{H}_{2} \mathrm{O}_{2}$-exposed diet control group as compared with nonexposed controls ( $p<0.001$, post hoc $t$ tests). These tests also revealed that no deficits were seen in ${ }^{45} \mathrm{Ca}$ recovery after exposure to $\mathrm{H}_{2} \mathrm{O}_{2}$ in any of the diet-fed groups (All $p$ values $>0.05$ in comparisons between non- $\mathrm{H}_{2} \mathrm{O}_{2}$-exposed and $\mathrm{H}_{2} \mathrm{O}_{2}$-treated groups for the spinach, vitamin $\mathrm{E}$, and strawberry groups, Fig. 4). Additionally, the spinach-fed, $\mathrm{H}_{2} \mathrm{O}_{2}$-exposed group showed greater recovery than either the vitamin E- or strawberry- $\mathrm{H}_{2} \mathrm{O}_{2}$-treated groups ( $p<0.01$ for both comparisons).

\section{Cognitive testing}

For the MWM, latency to find the platform, distance swam, and speed were calculated separately for trials 1 and 2. Subsequently, to analyze the effect of the diets on cognitive performance, ANOVAs were run only on data for days 3 and 4, because no difference was expected between the diet groups before this time, and because the rats were still learning the task (as seen by a significant effect of time). For trial 1, ANOVA showed a significant effect of diet group for latency $\left[F_{(3,71)}=3.39 ; p<0.05\right]$ and distance $\left[F_{(3,71)}=5.18 ; p<0.01\right]$ (Fig. 5). The group fed the spinach diet had a shorter latency to find the platform in the reference memory trial of the MWM compared with the control group $(p<0.05)$ (Fig. $5 A)$. Additionally, both the spinach and vitamin $E$ groups showed a shorter distance to the platform on trial 1 compared with the control group $(p<0.05)$ (Fig. 5B). These differences were not caused by swim speed, because there was no significant effect of diet group on this measure. There were also no differences between any of the diet groups on working memory (trial 2) performance.

\section{Oxidative stress}

As can be seen in Figure $6 A$, there were significant differences in DCF fluorescence among the various groups $\left[F_{(3,20)}=87.61 ; p<\right.$ $0.0001]$ in the striatum. In this regard, the striata obtained from the strawberry-supplemented group did not exhibit any increased level of OS protection relative to the control group $(p>0.05$ control vs strawberry group). Only the spinach and vitamin E groups showed greater native OS protection than controls $(p<$ 0.0001 for both spinach vs control and vitamin E vs control), whereas the vitamin $\mathrm{E}$ group showed less native OS protection than the spinach group $(p<0.007)$.

In the cerebellum (Fig. $6 B$ ), there were also significant differences in DCF fluorescence among the various groups $\left[F_{(3,42)}=\right.$ $156.62 ; p<0.0001]$, indicating increased native protection against oxidative stress in these groups. All of the supplemented groups differed from control $(p<0.0001)$, whereas the animals maintained on the high vitamin E-supplemented diet showed the highest protection ( $p<0.0001$ as compared with the strawberryand spinach-supplemented groups). The cerebellar tissue obtained from animals maintained on the strawberry-supplemented diet also showed less fluorescence (more antioxidant protection) than the spinach-supplemented group $(p<0.0001)$.

\section{GTPase activity}

The results with respect to age-induced decrements in carbacholstimulated GTPase activity differed from those of the other parameters in that the strawberry and the vitamin E supplementation prevented the decrements, whereas spinach did not [control vs spinach, $p>0.05$; control vs strawberry, $p<0.0001$; control vs vitamin $\mathrm{E}, p<0.05 ; F_{(3,20)}=12.6 ; p<0.0001$ overall]. The results expressed as $\Delta$ between basal and carbachol-stimulated GTPase activity are shown in Figure 7.

\section{DISCUSSION}

As indicated in the introductory remarks, there is an abundance of literature to suggest that diets high in fruits and vegetables are important in preventing or moderating such major disorders as cancer and heart disease. Even extracts of single foods such as garlic (Pinto et al., 1997) and tomato (lycopene; Sharoni et al., 1997) can have some antitumor properties. In the brain, evidence was also cited that indicated that it might be possible to reduce the deleterious effects of aging and AD through dietary supplemen- 


\section{CONTROL}

\section{GABA $18 \mathrm{nA}$}

A
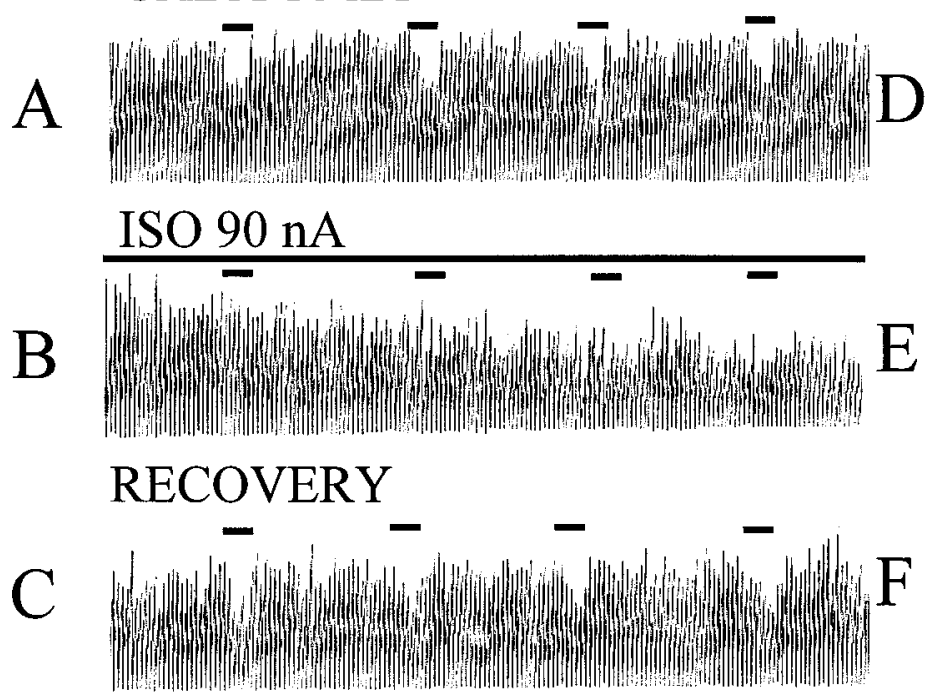

\section{STRAWBERRY}

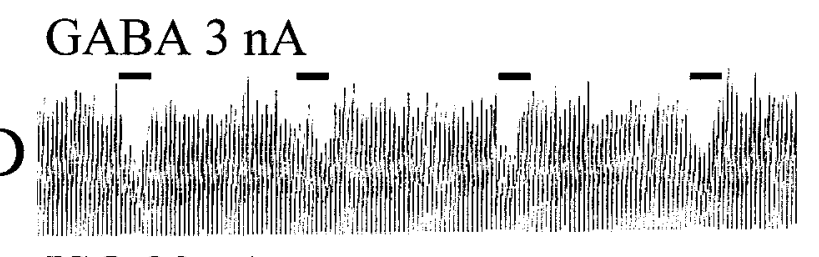

ISO $30 \mathrm{nA}$

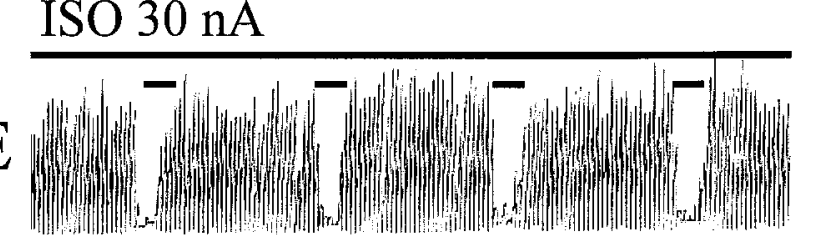

\section{RECOVERY}

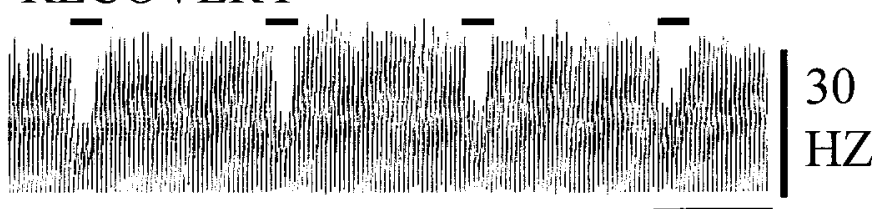

20 SEC

Figure 2. Examples of ratemeter records from extracellular recordings of Purkinje neurons from an aged rat maintained for 8 months (from 6-15 months of age) on a control $(A-C)$ or strawberry $(D-F)$ diet. In $A$ and $D$, the baseline response to GABA is shown. The dose of GABA was adjusted to produce a $15-30 \%$ inhibition of the Purkinje cell firing rate. In $B$ and $E$, isoproterenol was coapplied with GABA. In the control, aged rat, isoproterenol had no effect at lower doses (data not shown) and, at a high dose the GABA inhibition was reduced, and the baseline firing rate was diminished. In contrast, in the aged rat that was maintained on the strawberry diet, isoproterenol increased the GABA inhibition to $98 \%$. This is similar to what has been previously observed in young rats. $C$ and $F$ show recovery back to preisoproterenol levels of GABA inhibition. Bars above the ratemeter indicate the drug application times. The horizontal calibration bar indicates time in seconds, whereas the vertical calibration bar indicates the firing rate of the Purkinje neuron in action potentials per second.

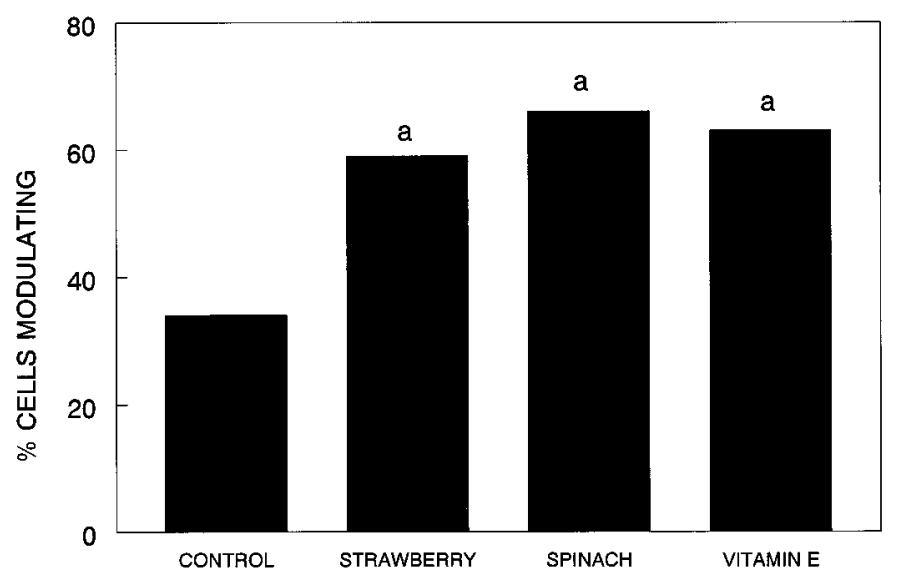

Figure 3. Mean isoproterenol facilitation of GABAergic inhibition of cerebellar Purkinje cells in animals maintained on control or various antioxidant diets for 8 months (6-15 months of age). For this figure, $a$ s differ from the control group at $p<0.05$. No antioxidant groups differed from each other.

tation with ginkgo biloba or vitamin E. In addition, recent studies have indicated that garlic extract was effective in preventing brain atrophy (Moriguchi et al., 1997) as well as learning and memory impairments (Nishiyama et al., 1997) in the senescenceaccelerated mouse.

Moreover, preliminary findings from our laboratories have suggested that fruit and vegetable extracts high in both flavonoid levels (e.g., spinach and strawberries) as well as total antioxidant

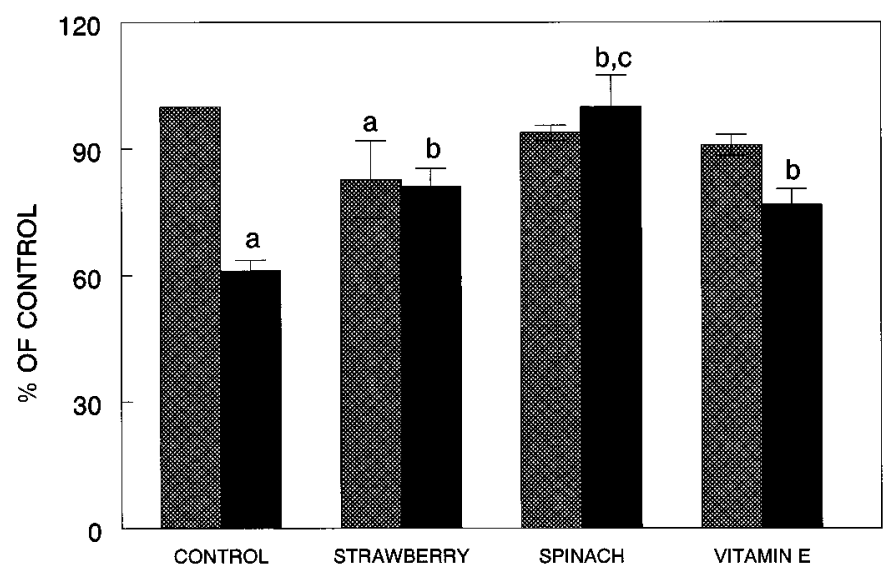

Figure 4. Calcium recovery in synaptosomes obtained from animals in the various diet groups and exposed to 0 or $300 \mu \mathrm{M} \mathrm{H} \mathrm{H}_{2} \mathrm{O}_{2}(15 \mathrm{~min})$ and depolarized with $60 \mathrm{~mm} \mathrm{KCl}$. For this figure, $a$ differs from untreated (no $\left.\mathrm{H}_{2} \mathrm{O}_{2}\right)$ control $(p<0.001), b$ differs from $\mathrm{H}_{2} \mathrm{O}_{2}$-treated control $(p<0.02$; $p<0.001$; and $p<0.05$, respectively), and $c$ differs from vitamin $\mathrm{E}$ ( $p<$ $0.01)$ or strawberry-fed $(p<0.01) \mathrm{H}_{2} \mathrm{O}_{2}$-treated groups.

activity, as assessed via the ORAC assay (Cao et al., 1995, 1996; Wang et al., 1996), also antagonize the deleterious "age-like" neuronal effects of $48 \mathrm{hr}$ of exposure to $100 \%$ normobaric $\mathrm{O}_{2}$. Rats fed diets containing these extracts for $6 \mathrm{wks}$ before exposure showed no loss in striatal muscarinic or cerebellar GABAergic receptor sensitivity (Chadman et al., 1997). These oxygeninduced decreases in neuronal function have been investigated in 

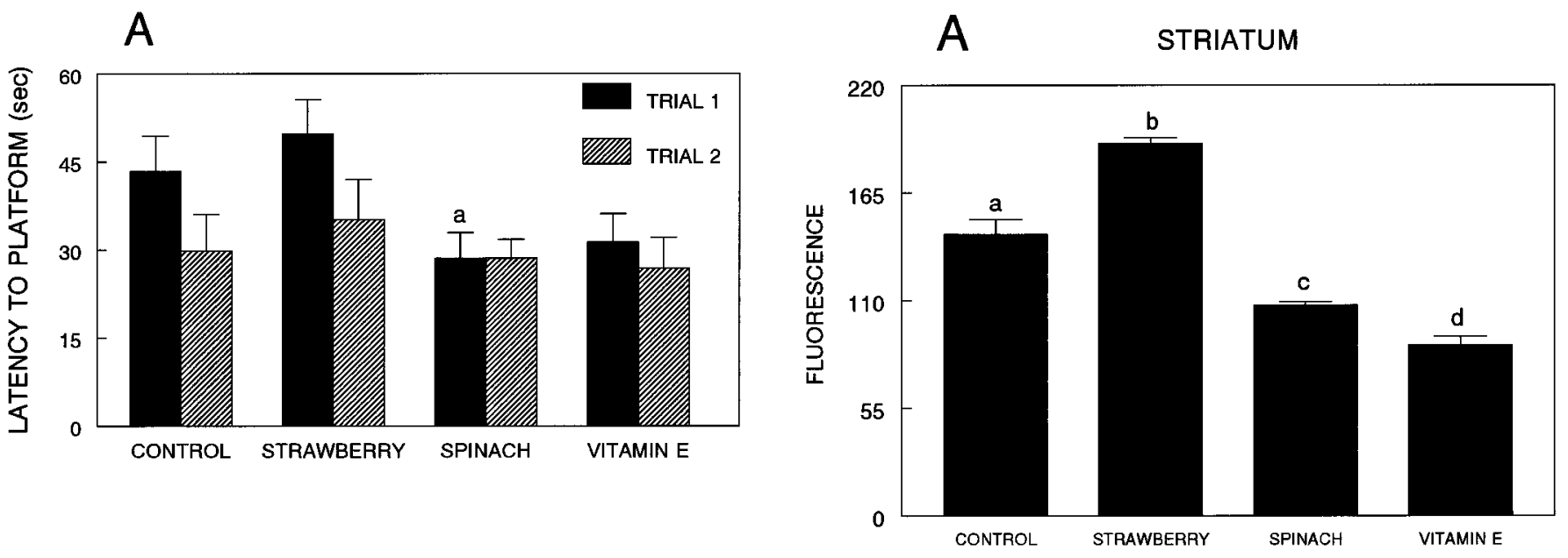

B
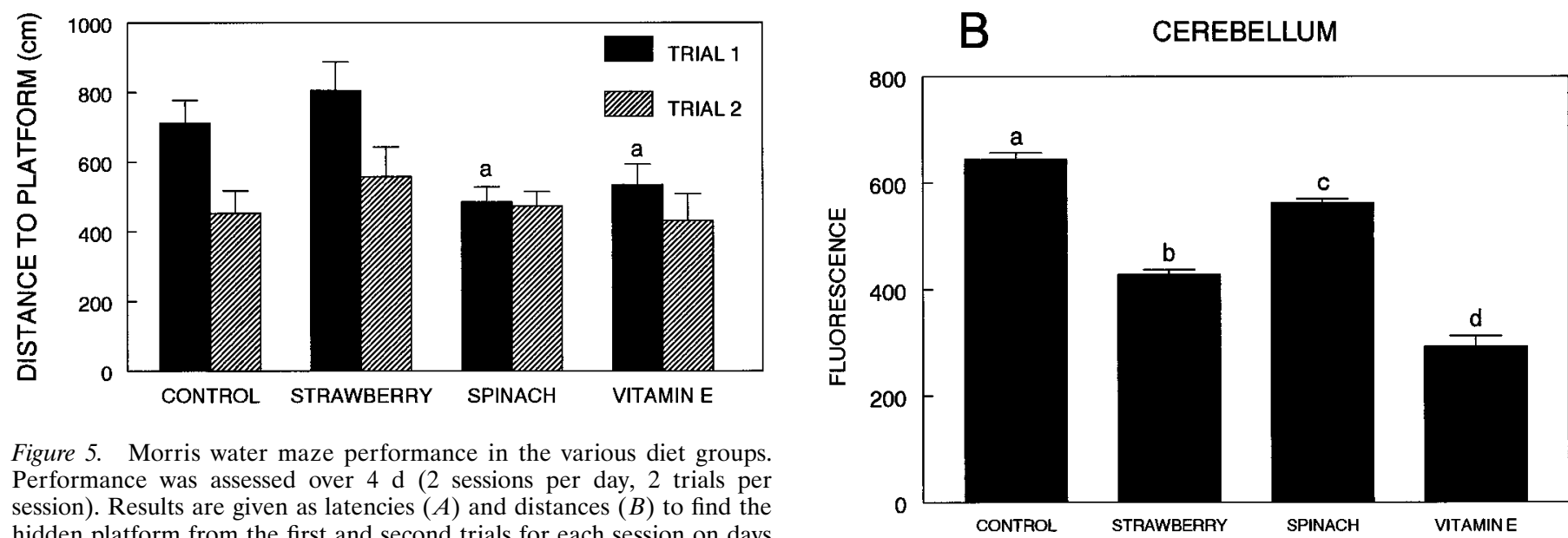

Figure 5. Morris water maze performance in the various diet groups. session). Results are given as latencies $(A)$ and distances $(B)$ to find the hidden platform from the first and second trials for each session on days 3 and 4. For this figure, as differ from the control group at $p<0.05$ (trial 1).

numerous experiments and have also been shown to be sensitive to aging and have been associated with behavioral deficits.

However, there is a paucity of research concerned with the positive effects of fruit and/or vegetable supplementation in retarding age-related neuronal and behavioral dysfunctions using age-valid tests. The results of these experiments have provided such evidence and have suggested, for the first time, that dietary supplementation with foods identified as being high in antioxidant activity (via ORAC) can retard the effects of aging on four rather diverse indices of neuronal and behavioral functions that are sensitive to both oxidative stress and aging.

Thus, each of these diets was effective in retarding the ageassociated deficits in muscarinic receptor sensitivity, as assessed via oxotremorine enhancement of striatal DA release; isoproteronal facilitation of GABAergic inhibition of cerebellar Purkinje neurons; calcium regulation; and Morris water maze performance. Spinach supplementation consistently produced the greatest retardation of the aging effects in calcium regulation, oxotremorine-enhanced $\mathrm{K}^{+}$-ERDA, and the onset of cognitive deficits; all three diets were similarly effective in preventing the loss of NE sensitivity in the Purkinje cells. In contrast to the other parameters, when decrements in carbachol-stimulated GTPase activity were assessed, the results indicated that the vitamin $\mathrm{E}$ and

Figure 6. Interaction of diets and oxidative stress in striatum $(A)$ and cerebellum $(B)$. Oxidative stress in brain tissue was evaluated by using DCFH-DA, as described in Material and Methods. Data for the formation of reactive oxygen species were obtained from 6-13 individual animals per group, performed with 6-10 replicates, and expressed as mean \pm SEM. For this figure, means not sharing a common letter are significantly different $(p<0.01)$.

strawberry-supplemented diets showed the greatest efficacy in preventing their onset.

We are presently attempting to delineate the sites of actions of the phytochemicals present in these foods and particular classes that are the most effective in preventing these age-related deficits. One important class may be the flavonoids. Flavonoids are recognized as one group of phytochemicals which include, among others: allium compounds (diallyl sulfide and allyl methyl trisulfide) and carotenoids ( $\alpha$-carotene, $\beta$-carotene, lutein, and lycopene). Because flavonoids are present to a considerable degree in vegetables and fruits, they make up an important part of the human diet (Kuhnau, 1976). Their daily intake has been estimated to be as high as $1 \mathrm{gm}$ per day, with the primary dietary source being vegetables. However, although some flavonoids may have higher antioxidant activity than others (Cao et al., 1997), it may be that ultimately it is the "Gestalt" of the myriad of interactions among various classes of phytochemicals present in foods with high ORAC activity that may confer this potent 


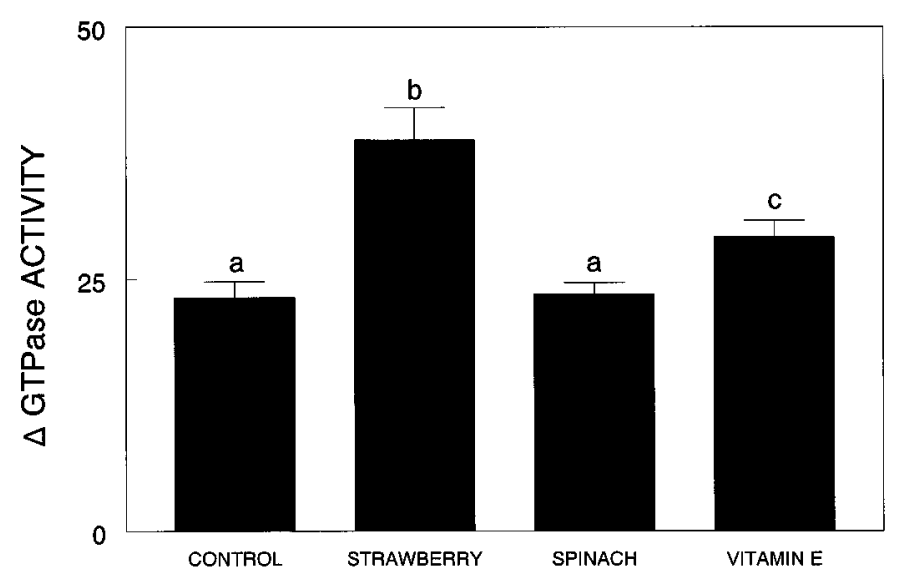

Figure 7. Differences (expressed as $\Delta \mathrm{G}$ from baseline) in carbacholstimulated low $K_{\mathrm{M}}$ GTPase activity from striatal slices obtained from the various diet groups (see Materials and Methods). For this figure, $b$ differs from the control, spinach, and vitamin E groups $(p<0.0001 ; p<0.0001$; and $p<0.003$, respectively), whereas $c$ differs from the control and spinach groups $(p<0.05)$.

antioxidant protection. In other words, "the whole is more than the sum of its parts".

One point that can be made in this regard is that preliminary analyses of the regional differences in vitamin $\mathrm{C}$ among cortical, hippocampal, cerebellar, and striatal tissues obtained from the diet groups in this study indicate that there are no differences as a function of diet. These findings indicate that the prevention of the age changes among the various diets are probably not the result of vitamin $\mathrm{C}$ contained in the strawberry or spinach extracts. Moreover, in a preliminary analysis of the brain levels of vitamin $\mathrm{E}$ among the various diets, only the high vitamin $\mathrm{E}$ diet increased regional brain levels of vitamin $\mathrm{E}$ relative to controls. However, the striata obtained from the animals maintained on the high vitamin $\mathrm{E}$ diet showed the lowest levels of vitamin $\mathrm{E}$ of any brain region examined, whereas the hippocampus showed the highest. Because the high vitamin E diet group showed significantly less protection against loss of oxotremorine enhancement of DA, Morris water maze performance, and striatal synaptosomal $\mathrm{Ca}^{2+}$ recovery relative to the spinach-supplemented group, these findings indicate that other phytochemicals (e.g., flavonoids) contained in the diets of the supplemented groups may be more effective in protecting against the deleterious effects of aging on these parameters.

However, given the findings with respect to the DCF analyses, it may be that factors other than those having to do with protection against oxidative stress may be involved. For example, in the cerebellum, whereas the supplemented diets were effective in increasing the level of OS protection (reduced DCF fluorescence), in all of the groups as compared with control the spinachsupplemented group had the lowest level of protection of any of the groups, although this supplementation significantly retarded the onset of loss of NE inhibition as a function of aging. In the striatum, the strawberry-supplemented group showed the lowest level of OS protection (highest fluorescence) but had the best protection against the loss of carbachol-stimulated GTPase activity of any group, whereas vitamin E did not necessarily provide the greatest long-term protection in any of the parameters examined but showed the greatest efficacy in reducing fluorescence in the DCF assessments in both the striatum and cerebellum. Thus, it may be that there are other effects of the phytochemicals contained in spinach and strawberries in addition to antioxidant protection. One of these may be alterations in membrane rigidity. It is known, for example, that flavonoids increase membrane fluidity (Ramassamy et al., 1993; Stoll et al., 1996; Halder and Bhaduri, 1998), and we have shown previously (Joseph et al., 1995) that by incubating striatal slices in $S$-adenosyl-Lmethionine, a potent membrane-fluidizing agent, we were able to reverse the age-related deficits in oxotremorine-enhanced $\mathrm{K}^{+}$ERDA. We are currently investigating whether the flavonoids contained in the strawberry- and spinach-supplemented diets, especially the anthocyanins, can have similar effects in these assessments.

In addition, attempts are being undertaken to determine whether these diets will also be effective in reversing the deleterious effects of aging on the above parameters as well as motor behavior. However, present findings, thus far, suggest that nutritional intervention with fruits and vegetables may play an important role in preventing or perhaps even reversing the effects of oxidative stress in aging on brain function.

\section{REFERENCES}

Amenta F, Cavallotti C, Franch F, Ricci A (1989) Muscarinic cholinergic receptors in the hippocampus of the aged rat: effects of longterm hydergine administration. Arch Int Pharmacodyn Ther 297:225-234.

Araki T, Kato H, Shuto K, Fujiwara T, Itoyama Y (1997) Effect of aging on dopaminergic receptors and uptake sites in the rat brain studied by receptor autoradiography. J Neurol Sci 148:131-137.

Araujo DM, Lapchak PA, Meaney MJ, Collier B, Quirion R (1990) Effects of aging on nicotinic and muscarinic autoreceptor function in the rat brain: relationship to presynaptic cholinergic markers and binding sites. J Neurosci 10:3069-3078.

Brandeis R, Brandys Y, Yehuda S (1989) The use of the Morris water maze in the study of memory and learning. Int J Neurosci 48:29-69.

Burnett DM, Bowyer JF, Masserano JM, Zahniser NR (1990) Effect of aging on alpha-1 adrenergic stimulation of phosphoinositide hydrolysis in various regions of rat brain. J Pharmacol Exp Ther 255:1265-1270.

Cao G, Verdon CP, Wu AHB, Wang H, Prior RL (1995) Automated oxygen radical absorbance capacity assay using the COBAS FARA II. Clin Chem 41:1738-1744.

Cao G, Sofic E, Prior R (1996) Antioxidant capacity of tea and common vegetables. J Agric Food Chem 44:3426-3431.

Cao G, Sofic E, Prior RL (1997) Antioxidant and prooxidant behavior of flavonoids: Structure-activity relationships. Free Radical Biol Med 22:749-760.

Carney JM, Smith CD, Carney AM, Butterfield DA (1994) Aging- and oxygen-induced modifications in brain biochemistry and behavior. Ann NY Acad Sci 738:44-53.

Cassel D, Selinger Z (1976) Catecholamine-stimulated GTPase activity in turkey erythrocyte membranes. Biochim Biophys Acta 452:538-551.

Chadman K, Joseph JA, Shukitt-Hale B, Prior R, Taglialatela G, Bickford PC (1997) Diets high in antioxidant activity prevent the deleterious effects of oxidative stress on signal transduction and nerve growth factor. Soc Neurosci Abstr 23:348.

Denisova NA, Erat SA, Kelly JF, Roth GS (1998) Differential effect of aging on cholesterol modulation of carbachol stimulated Low-Km GTPase in striatal synaptosomes. Exp Gerontol 33:249-265.

Doll R (1990) An overview of the epidemiological evidence linking diet and cancer. Proc Nutr Soc 49:119-131.

Dondi D, Maggi R, Limonta P, Martini L, Piva F (1992) Binding characteristics of delta opioid receptors in different regions of the brain of young and old male rats as studied with the highly selective ligand [D-Pen2-D-Pen5] enkephalin. Aging 4:69-75.

Egashira T, Takayama F, Yamanaka Y (1996) Effects of bifemelane on muscarinic receptors and choline acetyltransferase in the brains of aged rats following chronic cerebral hypoperfusion induced by permanent occlusion of bilateral carotid arteries. Jpn J Pharmacol 72:57-65. 
Finch CE, Cohen DM (1997) Aging, metabolism, and Alzheimer's disease: review and hypotheses. Exp Neurol 143:82-102.

Gage FH, Dunnett SB, Bjorklund A (1984) Spatial learning and motor deficits in aged rats. Neurobiol Aging 5:43-48.

Gallagher M, Pelleymounter MA (1988) Spatial learning deficits in old rats: A model for memory decline in the aged. Neurobiol Aging 9:549-556.

Gelbmann CM, Muller WE (1990) Specific decrease of high-affinity agonist states of alpha 2-adrenoceptors in the aging mouse brain. J Neural Transm 79:131-136.

Gould TJ, Bickford P (1997) Age-related deficits in the cerebellar beta adrenergic signal transduction cascade in Fischer 344 rats. J Pharmacol Exp Ther 281:965-971.

Gould TJ, Stromberg I, Bickford PC (1996) Decline in striatal dopamine D1 and D2 receptor activation in aged 344 rats. Neurobiol Aging 17:877-883.

Halder J, Bhaduri AN (1998) Protective role of black tea against oxidative damage of human red blood cells. Biochem Biophys Res Commun 244:903-907.

Hughes K (1995) Diet and coronary heart disease: a review. Ann Acad Med Singapore 24:224-229.

Ingram DK, Jucker M, Spangler EL (1994) Behavioral manifestations of aging. In: Pathobiology of the aging rat, Vol 2 (Mohr U, Cungworth DL, Capen CC, eds), pp 149-170. Washington, DC.

Jenner P (1996) Oxidative stress in Parkinson's disease and other neurodegenerative disorders. Pathol Biol 44:57-64.

Joseph JA, Berger RE, Engel BT, Roth GS (1978) Age-related changes in the nigrostriatum: A behavioral and biochemical analysis. J Gerontol 33:643-649.

Joseph JA, Dalton TK, Hunt WA (1988a) Age-related decrements in the muscarinic enhancement of $\mathrm{K}^{+}$-evoked release of endogenous striatal dopamine: An indicator of altered cholinergic-dopaminergic reciprocal inhibitory control in senescence. Brain Res 454:140-148.

Joseph JA, Dalton TK, Roth GS, Hunt WA (1988b) Alterations in muscarinic control of striatal dopamine autoreceptors in senescence: a deficit at the ligand-muscarinic receptor interface? Brain Res 454:149-155.

Joseph JA, Kowatch MA, Maki T, Roth GS (1990) Selective cross activation/inhibition of second messenger systems and the reduction of age-related deficits in the muscarinic control of dopamine release from perfused rat striata. Brain Res 537:40-48.

Joseph JA, Villalobos-Molina R, Yamagami K, Roth GS, Kelly J (1995) Age specific alterations in muscarinic stimulation of $\mathrm{K}^{+}$-evoked dopamine release from striatal slices by cholesterol and $S$-adenosyl-Lmethionine. Brain Res 673:185-193.

Joseph JA, Villalobos-Molina R, Denisova N, Erat S, Cutler R, Strain $\mathrm{J}$ G (1996) Age differences in sensitivity to $\mathrm{H}_{2} \mathrm{O}_{2}$-or NO-induced reductions in $\mathrm{K}^{+}$-evoked dopamine release from superfused striatal slices: reversals by $\mathrm{PBN}$ or Trolox. Free Radical Biol Med 20:821-830.

Joseph JA, Erat S, Denisova N, Villalobos-Molina R (1998) Receptor- and age-selective effects of dopamine oxidation on receptor-G-protein interactions in the striatum. Free Radical Biol Med 24:827-834.

Kanowski S, Herrmann WM, Stephan K, Wierich W, Horr R (1996) Proof of efficacy of the ginkgo biloba special extract EGb 761 in outpatients suffering from mild to moderate primary degenerative dementia of the Alzheimer type or multi-infarct dementia. Pharmacopsychiatry 29:47-56.

Kleijnen J, Knipschild P (1992a) Ginkgo biloba. Lancet 340:1136-1139.

Kleijnen J, Knipschild P (1992b) Ginkgo biloba for cerebral insufficiency. Br J Clin Pharmacol 34:352-358.

Kornhuber J, Schoppmeyer K, Bendig C, Riederer P (1996) Characterization of $\left[{ }^{3} \mathrm{H}\right]$ pentazocine binding sites in post-mortem human frontal cortex. J Neural Transm 103:45-53.

Kuhnau J (1976) The flavonoids. A class of semi-essential food components: their role in human nutrition. World Rev Nutr Diet 24:117-191.

Landfield PW, Eldridge JC (1994) The glucocorticoid hypothesis of agerelated hippocampal neurodegeneration: role of dysregulated intraneuronal $\mathrm{Ca}^{2+}$. Ann NY Acad Sci 746:308-321.

Lebel CP, Ischiropolos H, Bondy SC (1992) Evaluation of the probe $2^{\prime}, 7^{\prime}$ - dichlorofluorescein as an indicator of reactive oxygen species formation and oxidative stress. Chem Res Toxicol 5:227-231.

Leslie SW, Friedman MB, Wilcox RE, Elrod SV (1980) Acute and chronic effects of barbiturates on depolarization-induced calcium influx into rat synaptosomes. Brain Res 185:409-417.

Levine MS, Cepeda C (1998) Dopamine modulation of responses mediated by excitatory amino acids in the neostriatum. Adv Pharmacol 42:724-729.

Lowry OH, Rosebrough NJ, Farr AL, Randall RJ (1951) Protein measurement with the folin phenol reagent. J Biol Chem 193:256-275.

Mayne ST (1996) Beta-carotene, carotenoids and disease prevention in humans. FASEB J 10:690-701.

Meydani SN, Wu D, Santos MS, Hayek MG (1995) Antioxidants and immune response in aged persons: overview of present evidence. Am J Clin Nutr 62:1462S-1476S.

Migheli A, Cavalla P, Piva R, Giordana MT, Schiffer D (1994) Bcl-2 protein expression in aged brain and neurodegenerative diseases. NeuroReport 5:1906-1908.

Moriguchi T, Saito H, Nishiyama N (1997) Anti-aging effect of aged garlic extract in the inbred brain atrophy mouse model. Clin Exp Pharmacol Physiol 24:235-242.

Morris R (1984) Developments of a water-maze procedure for studying spatial learning in the rat. J Neurosci Methods 11:47-60.

Nagahara AH, Gill TM, Nicolle M, Gallagher M (1996) Alterations in opiate receptor binding in the hippocampus of aged Long-Evans rats. Brain Res 707:22-30.

Nishiyama N, Moriguchi T, Saito H (1997) Beneficial effects of aged garlic extract on learning and memory impairment in the senescenceaccelerated mouse. Exp Gerontol 32:149-160.

Ohkuwa TY, Sato Y, Naoi M (1997) Glutathione status and reactive oxygen generation in tissues of young and old exercised rats. Acta Physiol Scand 159:237-244.

Oyama YA, Hayashi H, Ueha T (1993) $\mathrm{Ca}^{+2}$-induced increase in oxidative metabolism of dissociated mammalian brain neurons: effect of extract of Ginkgo Biloba leaves. Jpn J Pharmacol 61:367-370.

Oyama Y, Fuchs PA, Katayama N, Noda K (1994) Myricetin and quercetin, the flavonoid constituents of Ginkgo biloba extract, greatly reduce oxidative metabolism in both resting and $\mathrm{Ca}^{+2}$-loaded brain neurons. Brain Res 635:125-129.

Pinto JT, Qiao C, Xing J, Rivilin RS, Protomastro MLW, Weissler ML, Tao Y, Thaler H, Heston WD (1997) The effects of garlic thioallyl derivatives on growth glutathione concentration and polyamine formation of human prostate carcinoma cells in culture. Am J Clin Nutr 66:398-405.

Rai SS, Shovlin C, Wesnes KA (1991) A double-blind placebo controlled study of Ginkgo biloba extract ('tanakan') in elderly outpatients with mild to moderate memory impairment. Curr Med Res Opin $12: 350-355$.

Ramassamy C, Girbe F, Christen Y, Costentin J (1993) Ginkgo Biloba extract EGb 761 or Trolox $\mathrm{C}$ prevent the ascorbic acid/ $\mathrm{Fe}^{2+}$-induced decrease in synaptosomal membrane fluidity. Free Radical Res Comm 19:341-350.

Rapp PR, Rosenberg RA, Gallagher M (1987) An evaluation of spatial information processing in aged rats. Behav Neurosci 101:3-12.

Roth GS, Joseph JA (1994) Cellular and molecular mechanisms of impaired dopaminergic function during aging. Ann NY Acad Sci 719:129-135.

Sharoni Y, Giron E, Rise M, Levy J (1997) Effects of lycopene-enriched tomato oleoresin on 7,12-dimethyl-benz[a]anthracene-induced rat mammary tumors. Cancer Detect Prev 21:118-123.

Sherman KA, Friedman E (1990) Pre-and post-synaptic cholinergic dysfunction in aged rodent brain regions: new findings and an interpretative review. Int J Dev Neurosci 8:689-708.

Stoll S, Scheur K, Pohl O, Muller WE (1996) Ginkgo biloba extract Egb761 independently improves changes in passive avoidance learning and brain membrane fluidity in the aging mouse. Pharmacopsychiatry 29:144-149.

Taylor A, Nowell T (1997) Oxidative stress and antioxidant function in relation to risk for cataract. Adv Pharmacol 38:515-536.

Ueda K, Shinohara S, Yagami T, Asakura K, Kawasaki K (1997) Amyloid $\beta$ protein potentiates $\mathrm{Ca}^{2+}$ influx through $\mathrm{L}$-type voltage-sensitive $\mathrm{Ca}^{2+}$ channels:a possible involvement of free radicals. $\mathrm{J}$ Neurochem 68:265-271.

Van der Staay FJ, de Jonge M (1993) Effects of age on water escape behavior and on repeated acquisition in rats. Behav Neural Biol 60:33-41.

Vannucchi MG, Goldman-Rakic PS (1991) Age-dependent decrease in 
the affinity of muscarinic M1 receptors in neocortex of rhesus monkeys. Proc Natl Acad Sci USA 88:11475-11479.

Viana GS, Marinho MM, Sousa FC (1992) Effect of piracetam administration on 3-H-N-methylscopolamine binding in cerebral cortex of young and old rats. Life Sci 50:971-977.

Volkow ND, Gur RC, Wang GJ, Fowler JS, Moberg PJ, Ding YS, Hitzemann R, Wang H, Cao G, Prior R (1996) Total antioxidant capacity of fruits. J Agric Food Chem 44:701-705.

Willett CW (1994a) Diet and health: what should we eat? Science 264:532-537.

Willett CW (1994b) Micronutrients and cancer risk. Am J Clin Nutr 59:162S-165S
Yamori Y, Horie R (1994) Community-based prevention of stroke: nutritional improvement in Japan. Health Rep 6:181-188.

Yeh YY, Gehman MF, Yeh SM (1993) Maternal dietary fish oil enriches docosahexaenoate levels in brain subcellular fractions of offspring. J Neurosci Res 35:218-226.

Yu BP (1994) Cellular defenses against damage from reactive oxygen species. Physiol Rev 76:139-162.

Yufu F, Egashira T, Yamanaka Y (1994) Age-related changes of cholinergic markers in the rat brain. Jpn J Pharmacol 66:247-255.

Zhang L, Joseph JA, Roth GS (1997) Effect of aging on vulnerability of striatal D1 and D2 dopamine receptor-containing neurons to kainic acid. Brain Res 763:264-266. 